\title{
Home-based genetic testing: a risky business?
}

\section{Kristen Reilly \& Shawn Slade}

\author{
University of Western Ontario
}

\section{Introduction}

Genetic tests are powerful medical tools that appraise the probability of disease $\mathrm{e}^{1}$. Presymptomatic tests identify gene mutations that lead to inevitable hereditary conditions such as Huntington's disease, while predispositional tests locate gene expressions that are risk factors assisting in the early identification of diseases such as cancer, heart disease, and Alzheimer's disease ${ }^{1,2}$. Best practice guidelines for the medical provision of genetic testing state that genetic tests must be accompanied by patient education and support or counselling ${ }^{1-3}$. Education prior to genetic testing ensures that the patient is aware of the risks and benefits and can subsequently provide informed consent ${ }^{1-4}$. Genetic counselling is the process through which health professionals help and support patients as they cope with and adapt to having, or being at risk of developing, a genetic condition ${ }^{3}$. Genetic education and counselling are critical to minimize negative effects of, and help patients cope with, test results.

\section{Psychosocial Impact of Genetic Testing}

A positive DNA test result can cause prolonged feelings of anxiety and worrying as well as worsened psychological functioning ${ }^{5}$. It may also influence an individual's reproductive choices, particularly when it is determined that they are carriers of incurable hereditary diseases such as Huntington's disease or cystic fibrosis ${ }^{3,6}$. The risks of genetic tests extend beyond the individual, affecting their social environments. For example, results of genetic testing can lead to disruption of familial relationships and other social consequences including loss of life insurance or employment ${ }^{1,2}$. Despite these serious implications, scientific and technological advances in the field of genetics are making genetic testing increasingly accessible to the general public ${ }^{2}$. Today, Canadians can purchase simple home-based genetic tests (HBGTs) online for the price of
\$199. Once purchased, consumers submit a small sample of saliva to identify over 200 genetic markers which provide genealogical health information on more than 100 health conditions that the customer can interpret however they see fit without the guidance of a healthcare professional'. Therefore, the authors of this paper explore the potential repercussions of widespread merchandizing of HBGTs and offer recommendations to ameliorate current practices and develop policies that protect consumer health.

\section{Current Practice of HBGT}

Alarmingly, Health Canada currently has no policies in place to regulate quality, reliability, or validity of HBGTs and without government regulation and standardization of these measures, the likelihood of erroneous tests results increases ${ }^{1}$. Both positive and negative genetic test results can precipitate monumental life changes; therefore, inaccurate results from HBGTs may cause individuals to make fallacious and irreversible decisions about their lifestyle, relationships, and employment ${ }^{4,6}$. For example, false negative HBGT results may lead people to avoid necessary medical advice or treatment ${ }^{1}$. In contrast, if a HBGT overstates the genetic basis of a disease or provides inconclusive results, an individual may overestimate their risk of disease and subsequently seek unwarranted screening services and clinical examinations $s^{1,8}$. This increased demand for medical attention congests doctors' offices, squanders health care dollars, and increases the burden on an already strained health care system ${ }^{8}$.

Furthermore, unlike medically administered genetic testing, businesses selling HBGTs are not obligated to obtain informed consent, provide education or offer counselling for genetic tests. ${ }^{1}$ Without adequate education and informed consent, individuals may not be aware of the implications of their HBGT results, which may increase the risk and severity of confusion, anxiety, and psychological distress 
over test results. Therefore, lack of government regulation and medical oversight of HBGTs can exacerbate the existing risks of genetic testing, causing greater implications for individuals and society as a whole $e^{1,2,9}$.

\section{Recommendations and Conclusions}

In accordance with the Canadian College of Medical Geneticist position on HBGT, it is recommended that only scientifically valid tests be offered, and the technical and clinical limitations of the testing including sensitivity, specificity, and utility in assessing health must be clearly stated in a manor understandable to the target market. ${ }^{10}$ Furthermore, the authors of this paper strongly recommend the implementation of obligatory policies that require HBGT services to: 1) provide information about the psychosocial risks of genetic testing, 2) disclose who has access and ownership to genetic sample and test results, and 3) obtain informed consent from consumers. Finally, since HBGTs are already marketed and distributed in Canada, the authors call for further research to be conducted in order to establish quality standards that ensure the accuracy of these tests. The Canadian health care system has best practices in place including patient education and counselling to mitigate negative consequences and protect the health and well being of patients that undergo genetic testing. Home-based genetic tests blur the line between patient and consumer. In light of this, private companies selling HBGTs for profit must also be held accountable for the implications of their products.

\section{References}

1. Williams J, Skirton H, Masny A. Ethics, policy, and educational issues in genetic testing. J Nurs Scholarsh. 2006;38(2):119-25.

2. Marteau T, Croyle R. Psychological responses to genetic testing. BMJ. 1998;316(7132):693-6.

3. Aatre R, Day S. Psychological issues in genetic testing for inherited cardiovascular diseases. Circ Cardiovasc Genet. 2011;4:81-90.

4. Sandor J. Genetic testing, genetic screening and privacy. In: Chadwick R, Shickle D, Ten Have H, Wiesing U. The Ethics of Genetic Screening. Netherlands:Springer;1999. 181-190.

5. Van Dijk S, Otten W, Tollenaar R, Van Asperen C, Tibben A. Putting it all behind: Long-term psychological impact of an inconclusive DNA test result for breast cancer. Genet Med. 2008;10(10):745-50.

6. Myers R. Huntington's disease genetics. NeuroRx. 2004;1(2):255-62.

7. Gayomali C. 23 and Me Expands into Canada [Internet]. Fast Company: Healthware; 2014 October 1 [cited 2015 March 23]. Available from http:// www.fastcompany.com/3036513/ healthware/23andme-expands-intocanada

8. Meiser B. "Psychological impact of genetic testing for cancer susceptibility: an update of the literature." Psycho-Oncology 2005;14(12):1060-74

9. French $\mathrm{M}$, Moore J. Harnessing genetics to prevent disease and improve health: A state policy guide. Washington, DC: The Partnership for Prevention; 2003. Available from: https://genes-r-us.uthscsa.edu/sites/ genes-r-us/files/resources/genetics/GeneticsGuide.pdf

10. Nelson N, Armstrong L, Richer J, Evans J, Lauzon J, McGillivray B, Bruyère H, Dougan S. CCMG Statement on Direct-to-Consumer Genetic Testing [Internet]. Ottawa: Canadian College of Medical Geneticists; 2011 Jan 20 [cited 2015 March 23]. Available from http://www.ccmg-ccgm. org/documents/Policies_etc/Pos_Statements/PosStmt_EPP_DTC FINAL_20Jan2011.pdf

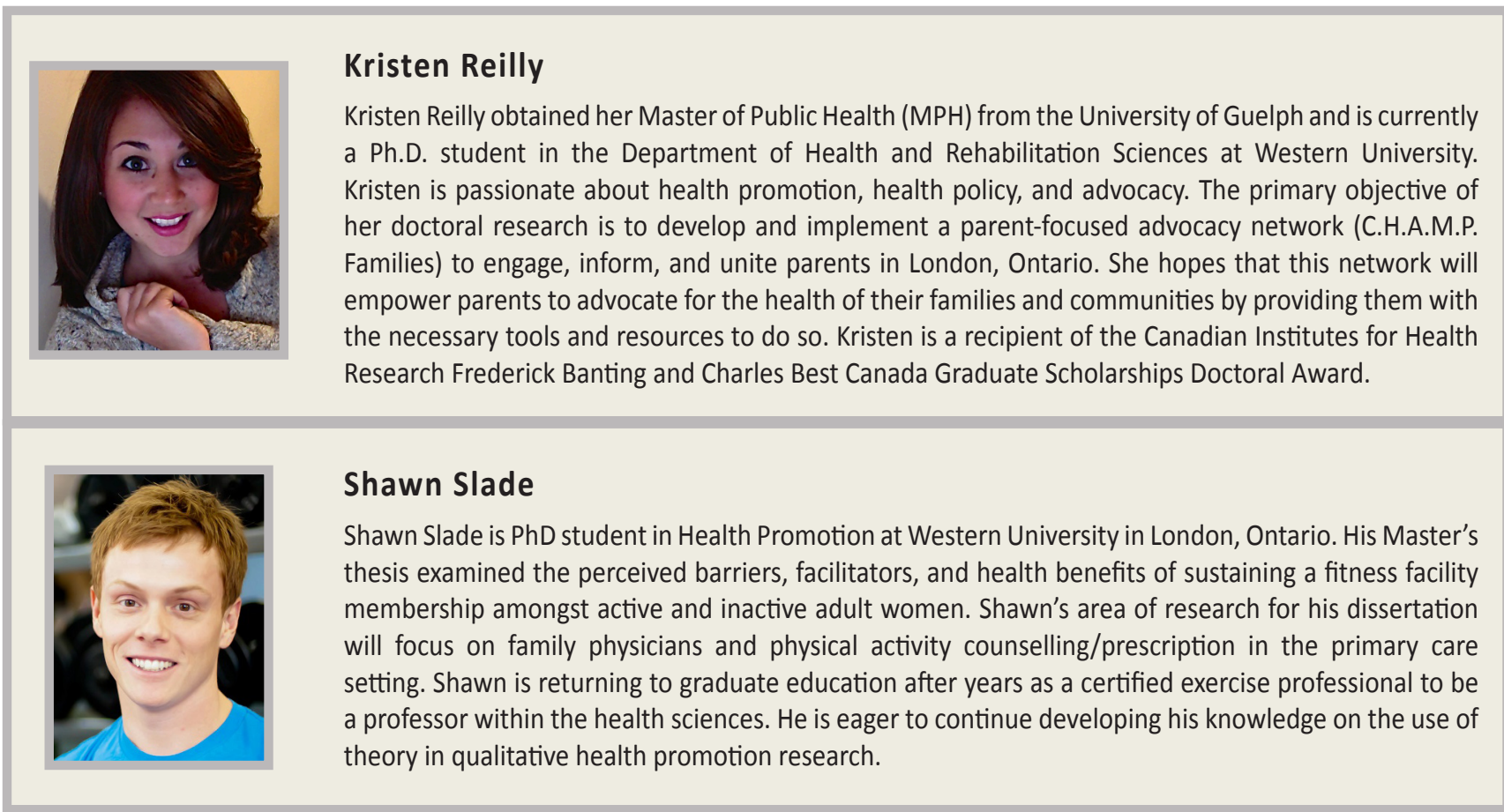

